\title{
Comparison of self-reported adherence to cervical and breast cancer screening guidelines in relation to the researcher's profession.
}

\author{
Maria Moudatsou' ${ }^{13}$, George Kritsotakis ${ }^{2}$, Antonis Koutis', Athanasios Alegakis ${ }^{4}$ Evangelia Panagoulopoulou', \\ Anastasios Philalithis' \\ 1 Department of Social Medicine, Medical School, University of Crete, Heraklion, \\ 2 Department of Nursing, Laboratory of Epidemiology, Prevention \& Management of Diseases, Hellenic Meditarranean University, Crete \\ 3 Department of Social work, Hellenic Meditarranean University, Crete \\ 4 Laboratory of Toxicology, Medical School, University of Crete, Heraklion
}

\begin{abstract}
Introduction: Self-reporting is a major and, in many cases, the only feasible method to use in cancer screening research. However, its validity has been questioned and numerous studies indicate that women over-report their participation in preventive Pap-test and mammography screenings.

Aim: The objective of this study was to determine whether individuals report in the same way their Pap-test and mammography screening behaviors when the interviews are conducted by researchers of different professions, in this case a social worker and a general practitioner.

Methods: Two studies assessing adherence to cervical and breast cancer screening guidelines were conducted during late 2006 - early 2007 in the same 114 women in Crete, Greece. Kappa coefficient was used to measure the agreement of participants' answers to the same questions between the two interviewers.

Results: Only 32 out of $90(35,5 \%)$ of the women replied that 'have had at least one' gynecological exam respectively in both studies (Kappa=0.189, $\mathrm{p}<0.001$ ). Agreement was also weak (Kappa=0.386 and 0.235) for self-reported mammography and Pap smear tests in the last 6 years, respectively. There were no significant differences in major demographic characteristics between women who provided, or not, the same answers in both interviewers, apart from the self-reported health status ( $\mathrm{p}=0.032$ ).

Conclusions: Women overestimated their self-reported adherence to cancer screening guidelines when the interviewer was a doctor once their responses were matched to those given to a social worker. The professional identities of the researchers that perform the data collection should be made explicit to make comparison across studies more accurate.
\end{abstract}

Keywords: adherence, cancer, gynecological tests, rater's agreement, self-reported health 


\section{RESEARCH STUDY}

\section{HIGHLIGHTS / KEY POINTS}

- The validity of self-reported data has been questioned.

- Numerous studies indicate that women over-report their participation in preventive Pap-test and mammography screenings, but the influence of the researcher has not been examined in detail yet.

- In this study, women overestimated their self-reported adherence to cancer screening guidelines when the interviewer was a doctor once their responses were matched to those given to a social worker.

- The professional identities of the researchers that perform the data collection should be made explicit to make comparison across studies more accurate.

\section{INTRODUCTION}

\section{B}

reast and cervical cancers are among the leading causes of mortality worldwide (American Cancer Society Detailed Guide 2010). Their morbidity and mortality can be reduced by early detection, mainly by using mammography and Pap smear tests (Dang et al. 2010, McPhee et al. 2002). Despite the fact that selfreporting is a major and, in many cases, the only feasible method to use in cancer screening research, its validity has been questioned and numerous studies indicate that women over-report their participation in preventive Pap-test and mammography screenings (Lofters et al. 2013, Smyth et al. 2007, Pizarro et al. 2002). A number of studies showed that self-reported screening responses could not be verified with medical records and were lessthan-accurate or biased (Fiscella et al. 2004, Newell et al. 2000, Rauscher et al. 2004, McPhee et al. 2002). Thus, study outcomes relying on faulty assumptions might produce misleading results (Pasick et al. 2004).

Many individual and social factors account for these discrepancies between self-reported and medical data, including, among others, inadequate communication and cultural differences between the interviewed people and the researchers, the ethnicity of the respondents, their minority and social disadvantage status, the site of care, the modality of the data collection, the way the questions are worded, and whether clarifications are given during the procedures (Allgood et al. 2014, Howard et al. 2009, Lofters et al. 2013, McPhee et al. 2002, Newell et al. 2000, Pasick et al. 2004). Additionally, it is common for women to underestimate the time since their last mammography or pap smear test, when they are asked retrospectively, and events are reported as being more recent than they actually are (Bowman et al. 1997, Chiquette et al. 2012, Walker et al. 2013).

Research questions relevant to screening issues are sometimes quite complicated for the general population and respondents may misunderstand the relevant concepts. When respondents perceive that screening tests fall under the same category, such as prevention of cancer in general, misreporting might occur, because they lack the knowledge to distinguish which screening test was performed (Vernon et al. 2004). In this case, interviewees who are more knowledgeable about cancer are more accurate in their screening self-reports (Chiquette et al. 2012).

Fiscella et al. (2004) suggested that different wording of the questions affected the results of mammography screening. Whenever respondents were unsure of the meaning of a question, they preferred to agree with the interviewer than appearing foolish and undermining their social status by providing a wrong answer or asking for a clarification (Vernon et al. 2004). The study of Trigoni et al. (2008) supported these results and suggested that if women lack the knowledge for understanding the research questions about their screening behavior, they increase the bias in their responses.

Central role in self-report bias when recalling information regarding screening events, involve cognitive processes such as conscious adjustment of the responses to control for the amount of information revealed (Newell et al. 2000, Vernon et al. 2004). Respondents usually give socially desirable questions when answering sensitive topics, like screening adherence, because they need to present themselves to the interviewers in a favorable manner (Smyth et al. 2007). The role of the researchers, in the cases of interviewing on cancer screening without validating the self-reported responses with medical records, is crucial because they should appreciate if interviewed people are able to understand the research questions or they need further instructions.

The aim of this study was to determine whether the same individuals report in the same way their test-pap and mammography screening behaviors, when the interviews are conducted by researchers of different professions, in this case a social worker and a general practitioner.

\section{METHODS}

\section{Study characteristics}

Two cross-sectional studies assessing adherence to cervical and breast cancer screening guidelines were conducted during late 2006 - early 2007 in the same individuals in an agricultural area of Crete, Greece (Municipality of Gorgolaini). (Panagoulopoulou et al. 2009, Moudatsou et al. 2014). The municipality 


\section{RESEARCH STUDY}

comprises six villages with around 3000 inhabitants (National Statistics Organisation Census 2011). The economy of this district depends largely on agriculture. There is free access to the public Primary Health Care (PHC) services, which are provided by three local medical offices.

Questionnaires in both studies included questions concerning demographic data such as age, educational level, occupation, marital status, number of children, income and place of residence. In both studies the participants were also asked to self-report on «Have you ever had any gynecological exams?» and «How many Pap smears and mammograms have you had in the last 6 years?». The main researcher conducting the interviews and the data collection was a General Practitioner in the first study (Panagoulopoulou et al. 2009) and a social worker in the second study (Moudatsou et al. 2014).

\section{Sample Selection and Sample Size}

In both studies, the sample consisted of the same 145 women aged from $35-75$ years old, residents in the same area for at least ten years and of Greek origin. They were selected using a random generator function with finite sampling from the total population of 592 women of the 2001 electoral register. The whole procedure of selection and sample size can be found in more details in Panagoulopoulou et al., (2009), and Moudatsou et al., (2014). Briefly the sample size and sample selection for both studies are described in Table 1.

\section{Statistical Methods}

Mean and standard deviation was used for describing continuous data, while counts and \% proportions were used for discrete data. Kappa coefficient was used to measure the agreement of participants' answers to the same questions between the two interviewers (general doctor and social worker). IBM SPSS Statistics 20.0 was used for statistical analysis and a level of 0.05 was set as significant.

\section{RESULTS}

The total number of participants, which were eligible for inclusion in this comparative analysis, was 114. There were no significant differences in major demographic variables between the eligible and the non-eligible samples for analysis [age $(55>$ or $<55$ ) (Fishers' $p=0.413$ ), income $(>$ or $<500 €$ ) (Fisher's $\mathrm{p}=0.062$ ), family status (married or not) (Fishers' $\mathrm{p}=0.070$ ) (Data not shown in table)].

The associations and the agreement between the answers of the participants given in a doctor and a social worker are presented in Table 2 . There is a slight agreement (Kappa $=0.189, \mathrm{p}<0.001)$ between the answers given in the question «Have you ever had gynecological exams?» in both interviewers (General Practitioner and social worker). In more detail, 24 out of $24(100 \%)$ and 32 out of $90(35,5 \%)$ women replied that they 'did not have' and 'have had at least one' gynecological exam respectively in both studies. The agreement coefficient for self-reported adherence to screening guidelines between the two studies was also weak (Kappa=0.386 and 0.235) when we evaluated mammography and Pap smear tests in the last 6 years, respectively.

Furthermore, participants were categorised in two groups. The first group included 56 women who provided similar answers in both raters in the question "have you ever had gynecological exams?". The second group consisting of 58 women did not give similar answers in the same question. The comparisons of their characteristics are shown in Table 3. There were no significant differences between the two groups in their demographic characteristics lage $p=0.255$, marital status $p=0.522$, number of children $p=0.436$, educational level $p=0.140$, self-reported income $p=0.806$ and working status $p=0.759$ ). Only women that self-reported better health status had higher possibilities of providing the same answers in both studies (63.9\%) ( $p=0.032)$.

\section{DISCUSSION}

The vast majority of current bibliography supports that the results of self-reported screening are overestimated when compared to medical records (Vernon et al. 2004, Coplan et al. 2003, Howard et al. 2009). However, this is one of the very few studies to estimate the differences in selfreported adherence to screening guidelines attributed to different health care professionals. Our study suggests that women overestimated their self-reported adherence to cancer screening guidelines when the interviewer was a General Practitioner once their responses were matched to those given to a social worker.

Primary health care physicians have a crucial role in the delivery of screening services through advising, recommending, performing and referring women for screening (Trigoni et al. 2008). Women may feel embarrassed and uncomfortable to let doctors know that they have not followed their recommendations and thus provide more social desirable answers to them. Women might also overestimate their screening behavior when talking to physicians, because if they gave accurate answers about their screening behaviors, there are more possibilities that the physicians would try to persuade them to perform the necessary screening tests. The difference between physicians and social workers is 


\section{RESEARCH STUDY}

that, in the case of physicians, women will be asked to provide the results of the tests to get relevant feedback in a future consultation, and thus, they will need to admit that they have not performed the recommended tests. In the case of social workers, this is not expected because they are not the ones to provide the medical feedback and women may feel that in this way they are released of the responsibility of adherence the screening rules (Smyth et al. 2007).

Another possible explanation for the higher percentage of women admitting that they had not performed the preventive tests to the social worker and not to the General Practitioner may be related to the different scientific approaches and professional identity of these professions: a key theme in social work theory and practice is the empathetic skills, and the ability to identify peoples' experiences and actively understand the respondents' perspectives (Decety \& Jackson 2004, Trevithick 2003, Wickman \& Cambell 2003). An empathy-driven attitude includes affective responses and cognitive processing that might enable individuals to mirror effectively their responses (Gerdes \& Segal 2009). Assessment cannot be effective unless there has been attention to a process of engagement and rapport building with the respondents (Morrison 2006).

Consequently, a social worker may be better prepared to elucidate more accurate screening behaviors from the women. This empathetic relationship might enable the women to give responses that reflect more correctly their real screening behaviours for Pap-test and mammography to a social worker. In addition, social workers may be better prepared to understand possible misunderstandings of the women and then give them more accurate instructions for answering the research questions (Ames \& Kammrath 2004). This is in line with Derrett and Colhoum (2011) and Simon et al. (2006), that suggested that the quality of the interaction between the interviewers and the respondents might influence the results of a study.

On the other hand, doctor may have paternalistic relationship with his/her patients. S/he may act as a "parent" figure that makes decisions for them. These forms of relationship traditionally characterized medical consultation and, in many cases, patients may feel comfortable from not having to worry about decision making (Morgan 2003). The problem in this case is that a large number of patients leave the consultation without asking questions about things that are troubling to them (Barry et al. 2000). It is difficult for patients to convey dissatisfaction during the consultation process because they think that doctors will not listen to them (Morgan 2003). A recent qualitative study based on 35 patients, who assessed their communication with doctors, found that only four of them have voiced all their concerns during consultation (Barry et al. 2000).

Women, who self-reported good or very good health, had the highest agreement in their reports of adherence to breast and cervical cancer screening guidelines. A possible explanation is that women with bad subjective health might have actual health problems that are not related to cancer. In this case they may not want to add more health problems in their daily routines, or to avoid further contacts with the health care system, avoiding stating their true adherence behaviors.

\section{Limitations}

Although our findings provide support that the professional role of the researcher is crucial to the accuracy of self-reported mammography and Pap-test screening, they are subject to some limitations. The first is dependent on our difficulty to access the accuracy of self-reported mammography and Pap-test screening with medical records. In this case, we could have the ability to make comparisons on the accuracy of selfreported screening based on medical data. Additionally, there is the possibility that the differences noted in this study could be attributed to personal characteristics of the researchers, and not their professional identity, although the differences are quite significant to be attributed only to individual characteristics and not to social desirability bias. This study evaluated only women and not men. Given the vast majority of literature documenting differences between men and women in a range of health outcomes (Kritsotakis et al 2016, 2018), we cannot know if the results apply to men as well.

\section{CONCLUSION}

The results of this study illustrate that women overestimate their screening adherence when a General Practitioner, compared to a social worker, makes the assessment. In line with the results presented in current literature and in this study, researchers have a key role on the measurement of self-reported screening adherence and studies should make explicit the professional identities of the researchers that performed the data collection, to make comparison across studies more accurate. Interviewers should also be sensitive in cognitive and culture issues relating to screening process that might influence the respondents' bias.

Future studies should be encouraged to assess in depth the reasons that make women overestimate their self-reported screening adherence and to elucidate whether these differences exist when other health care professionals, e.g. nurses, participate in data collection process and to compare them to medical records. 
REFERENCES

Allgood K.L, Rauscher G.H., Whitman S., Vasquez-Jones G. \& Shah A.M. (2014). Validating self-reported mammography use in vulnerable communities: findings and recommendations. Cancer Epidemiology Biomarkers Prevention 23:1649-58.

American Cancer Society Detailed Guide: (2010) Cervical cancer: what are the key statistics about cervical cancer? www.cancer.org/ Cancer/CervicalCancer/DetailedGuide/.

Ames D.R. \& Kammrath L.K. (2004). Mind-reading and metacognition: Narcissism not actual competence predicts self estimated ability. Journal of Non-verbal Behavior 28: 187- 209.

Barry C.A., Bradley C.P., Britten N. \& Stevenson F.A. (2000). Patients' unvoiced agendas in general practice consultations: Qualitative study. BMJ 320:1245-1250.

Bowman J.A., Sanson-Fisher R. \& Redman S. (1997). The accuracy of self-reported pap smear utilisation. Social Science Medicine 44:969-76.

Burke N.J., Bird J.A., Clark M.A., Rakowski W., Guerra C., Barker C.J. \& Pasick R.J. (2009). Social and cultural meaning of self-efficacy. Health Education Behavior 36: 111- 128.

Chiquette J., Despiens C., Larouche G., Bouchard K., Simard J. \& Dorral M. (2012). Self - reported mammography use following BRCA $1 / 2$ genetic testing may be overestimated. Family Cancer 11: 27-32.

Coplan L.S., Mandelson M.T. \& Anderson L.A. (2003). Validity of self reported mammography: Examing recall and covariates among older women in a health maintenance organization. American Journal of Epidemiology 157: 267-272.

Dang J., Lee J. \& Tran J.H. (2010). Knowledge, attitudes and beliefs regarding breast and cancer screening among Cambodian, Laotian, Thai and Tongan women. Journal of Cancer Education 25 595-601.

Decety J. \& Jackson P.L. (2004). The functional architecture of human empathy. Behavior and Cognitive Neuroscience Review 7: 71-100.

Derrett S. \& Colhoun S. (2011). Being a quantitative interviewer: Qualitatively exploring interviewers' experience in a longitudinal cohort study. BMC Medical Research Methodology 11: 165- 175.

Fiscella K., Franks P. \& Meldrum S. (2004). Estimating racial / ethnic disparity in mammography rates: It all depends on how you ask the questions. Preventive Medicine 39: 399- 403.

Freedberg S. (2007). Re-examining empathy: A relational -feminist point of view. Social Worker 52: 251-259.

Gerdes K.E. \& Segal E.A. (2009). A social work model of empathy. Advances in Social Work 10: 114-127.

Griva F., Anagnostopoulos F. \& Madoglou S. (2009) Mammography screening and theory of planned behaviour: Suggestions toward an extended model of prediction. Women Health 49: 622-681.

Howard M., Agarwal G. \& Lytwyn A. (2009). Accuracy of self - reports of pap and mammography screening compared to medical record: A meta analysis. Cancer Causes Control 20: 1-13

Kritsotakis G., Konstantinidis T., Androulaki Z., Rizou E., Asprogeraka E.M. \& Pitsouni V. (2018). The relationship between smoking and convivial, intimate and negative coping alcohol consumption in young adults. Journal of Clinical Nursing 27(13-14):2710-2718. doi: $10.1111 /$ jocn. 13889

Kritsotakis G., Koutis A., Alegakis A. \& Philalithis A.E. (2008). Development of the social capital questionnaire in Greece. Research in Nursing \& Health 31, 217-225.

Kritsotakis G., Psarrou M., Vassilaki M., Androulaki Z. \& Philalithis A.E. (2016). Gender differences in the prevalence and clustering of multiple health risk behaviours in young adults. Journal of Advanced Nursing 72(9), 2098-2113. doi: 10.1111/jan.12981

Kritsotakis G., Antoniadou E., Koutra K., Koutis A., Philalithis A. (2010). Cognitive validation of the Social Capital Questionnaire in Greece. Nosileftiki 49, 274-285 (in Greek)

Lofters A.K., Moineddin R., Hwang S.W. \& Glazier R.H. (2013). Does social disadvantage affect the validity of self-report for cervical cancer screening? International Journal of Women's Health 5: 2933.

Masterson E.A., Hopenhayan C. \& Christian W.J. (2009). Self-reported mental health status and recent mammography. Journal of Women's Health 19: 1569- 1576.

McPhee S.J., Nquyen T.T., Shema S.J., Nquyen B., Somkin C., Vo P., Pasick R. (2002). Validation of recall of breast and cervical cancer screening by women in an ethnically diverse population. Preventive Medicine 35: 463-473.

Walker M.J., Chiarelli A.M., Mirea L., Glendon G., Ritvo P., Andruilis I.L. \& Knight J.A. (2013). Accuracy of Self-Reported Screening Mammography Use: Examining Recall among Female Relatives from the Ontario Site of the Breast Cancer Family Registry. ISRN Oncology, vol. 2013, Article ID 810573, doi:10.1155/2013/810573

Morgan M. The Doctor- patient relationship, 5th edn. London: Elsevier, 2003.

Morisson T. (2006). Emotional intelligence emotion and social work: Context characteristics, complications and contribution. British Journal of Social Work 37: 245- 263.

Moudatsou M., Kritsotakis G., Alegakis A., Koutis A. \& Philalithis A. (2014). Social Capital and Adherence to cervical and breast cancer screening guidelines: a cross- sectional study in rural Crete. Health Care in the Community 22: 395-404.

National Statistics Organisation Census (2011) Available at: www. statistics.gr/portal/page/portal/ESYE/BUCKET/ General/NWS_ CENSUS_310712_GR.pdf

Newell S., Girgis A., Sanson-Fisher R. \& Ireland M. (2000). Accuracy of patients' recall of pap and cholesterol screening. American Journal of Public Health 90: 1431-1435

O' Keefe P.J. Persuasion: theory and research, 2th edn. USA: Sage Publication, 2002

Panagoulopoulou E., Alegakis A., Mourad T.A., Sanidas E., Makrigianakis A. \& Philalithis A. (2009). The role of general practitioners in promoting cervical cancer screening: A field survey in a rural area of Crete, Greece. European Journal of Cancer Prevention 19:160- 166

Pasick R.J., Hiatt R.A. \& Paskett D. (2004). Lessons learned from community-based cancer screening intervention research. Cancer 101: 1146- 1164

Pizarro J., Schneider T.R. \& Salovey P. (2002) A source of error in selfreports of pap test utilization. Journal of Community Health 27: 351-356.

Rauscher G.H., Earp J.A. \& O'Malley M. (2004). Relation between intervention exposures, changes in attitudes, and mammography use in the North Carolina breast cancer screening program. Cancer Epidemiology Biomarkers Prevention 13: 741- 747.

Rothery M. \& Tutty L. (2001). Client-Centered Theory. In: Lehmann $P$, Coady N, eds. Theoretical Perspectives for Direct Social Work Practice: A Generalisteclectic Approach, 2th edn. New York Springer: pp.223-239

Simon T.R., Mercy J.A. \& Barker L. (2006). Can we talk? Importance of random- digit-dial surveys for injury prevention research. Preventive Medicine 5: 406- 410.

Simou E., Maniadakis N., Pallis A., Foundoulakis E. \& Kourlapa G. (2010). Factors associated with use of pap smear testing in Greece. Journal of Women's Health 19:1577-1585.

Skovholt T. (2005). The cycle of caring: A model of expertise in the helping professions. Journal of Mental Health Counseling 27: 8293.

Smith A. (2006). Cognitive empathy and emotional empathy in human behaviour and evolution. Psychology Research 56: 3-21.

Smyth M.J., Webb M.S. \& Oikawa M. Report of cancer-related behaviors, 1th edn. Syracuse: Syracuse University, 2007.

Tolma E.L., Reininger B.M., Ureda J. \& Evans A. (2003). Cognitive motivations associated with screening mammography in Cyprus. Preventive Medicine 36: 363-373 
Trevithick P. (2003). Effective relationship-based practice: A theoretical explanation. Journal of Social Work Practice 17: 163-176.

Trigoni M., Griffiths F., Tsiftsis D., Koumantakis E., Green E. \& Lionis C. (2008). Mammography screening: Views from women and primary care physician in Crete. BMC Women's Health 8: 20-32.

Turner K. (2009). Mindfulness: The present moment in clinical social work. Clinical Social Work Journal 37: 95- 103

Vernon S.W., Briss P.A., Tiro J.A. \& Warnecke R.B. (2004). Some methodological lessons learned from cancer screening research and practice. Cancer 101: 1131-1145.

Viera A.J. \& Garrett J.M. (2005). Understanding interobserver agreement: The Kappa statistic. Family Medicine 37:360-363.

Wampold B.E. (2007). Psychotherapy: The humanistic (and effective) treatment. American Psychology 62:857- 873.

Wickman S.A. \& Campbell C. (2003). An analysis of how Carl Rogers enacted client-centered conversation with Gloria. Journal of Counseling Dev 81: 178- 189.

\begin{tabular}{|c|c|c|c|c|c|}
\hline & Interviewer & Period & Questionnaire & Sample & Participants \\
\hline $\begin{array}{l}\text { Study } 1 \\
\text { Panagoulopoulou } \\
\text { et al } 2009\end{array}$ & General Doctor & End 2006- 2007 & $\begin{array}{l}\text { + Use and knowledge of } \\
\text { gynecological examinations } \\
\text { + Random selection }\end{array}$ & $\begin{array}{l}\text { + Gorgolaini } \\
\text { municipality }\end{array}$ & $\begin{array}{l}125 \text { women aged } \\
35-75 \text { years old }\end{array}$ \\
\hline $\begin{array}{l}\text { Study } 2 \\
\text { Moudatsou et al } \\
2014\end{array}$ & Social Worker & $\begin{array}{l}\text { The same as in } \\
\text { Study } 1\end{array}$ & $\begin{array}{l}\text { The same as in Study } 1 \\
\text { +Social capital questionnaire } \\
\text { (SCQ-Greek) (Kritsotakis et } \\
\text { al 2008, 2010) } \\
\text { The same as in Study } 1\end{array}$ & $\begin{array}{l}\text { The same as in } \\
\text { Study } 1\end{array}$ & $\begin{array}{l}\text { The same as in } \\
\text { Study } 1\end{array}$ \\
\hline & Sample size & Participation & \multicolumn{3}{|c|}{ Questions related to the use and knowledge } \\
\hline $\begin{array}{l}\text { Study } 1 \\
\text { Panagoulopoulou } \\
\text { et al } 2009\end{array}$ & $\begin{array}{l}145 \text { selected } \\
22 \text { excluded } \\
3 \text { refused }\end{array}$ & $97.5 \%$ & \multicolumn{3}{|c|}{$\begin{array}{l}\text { - How many Pap smears have you had in the last } 6 \text { years? } \\
\text { - How many mammographies have you had in the last } 6 \text { years? } \\
\text { - Have you ever had a Pap smear? } \\
\text { - Have you ever had a mammography? }\end{array}$} \\
\hline $\begin{array}{l}\text { Study } 2 \\
\text { Moudatsou et al } \\
2014\end{array}$ & $\begin{array}{l}145 \text { selected } \\
19 \text { excluded } \\
6 \text { refused }\end{array}$ & $97.5 \%$ & \multicolumn{3}{|c|}{$\begin{array}{l}\text { - Do you know if there are screening tests for the prevention of breast } \\
\text { and cervical cancer? } \\
\text { - How many Pap smears and mammograms have you had in the last } 6 \\
\text { years? } \\
\text { - Have you ever had a Pap smear? } \\
\text { - Have you ever had a mammography? }\end{array}$} \\
\hline
\end{tabular}


Table 2. Agreement between participant's self-reported adherence as answered to a general practitioner and a social worker measured by Cohen's Kappa.

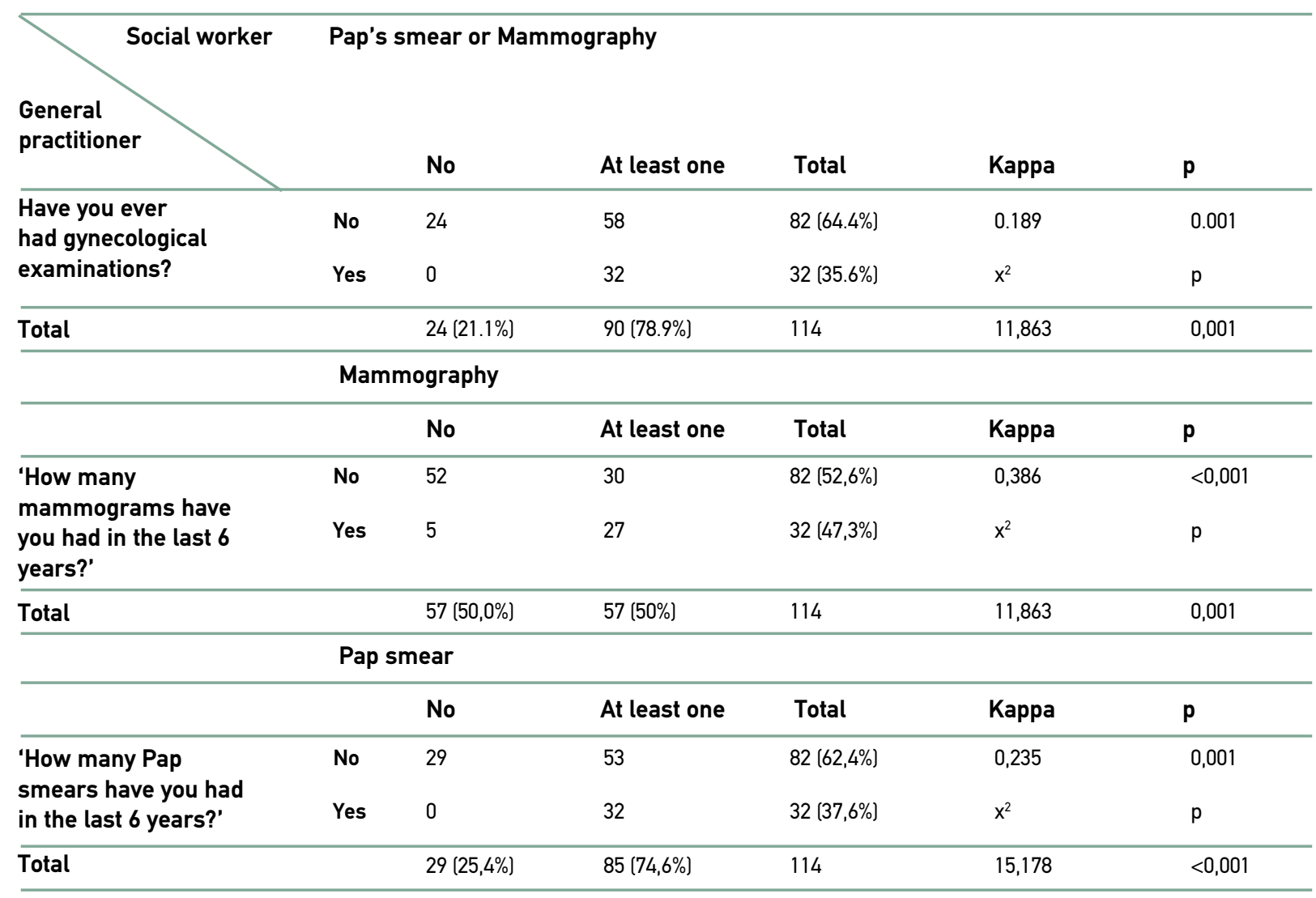




\section{RESEARCH STUDY}

Table 3. Characteristics of the women that provided and did not provide the same answers in the two interviewers.

\begin{tabular}{|c|c|c|c|c|c|c|c|}
\hline & & \multicolumn{6}{|c|}{$\begin{array}{l}\text { Have you ever had } \\
\text { gynaecological exams }\end{array}$} \\
\hline & & \multicolumn{2}{|c|}{ Agreement } & \multicolumn{2}{|c|}{ Non-Agreement } & & \multirow{2}{*}{$\begin{array}{r}\text { Total } \\
\mathbf{p}\end{array}$} \\
\hline & & $\%$ & & & $\%$ & & \\
\hline \multirow[t]{4}{*}{ Age groups } & $<=45$ & 1 & $57.9 \%$ & & $42.1 \%$ & 9 & 0.255 \\
\hline & $46-55$ & 3 & $56.5 \%$ & 0 & $43.5 \%$ & 3 & \\
\hline & $56-65$ & 1 & $34.4 \%$ & 1 & $65.6 \%$ & 2 & \\
\hline & $66+$ & 1 & $52.5 \%$ & 9 & $47.5 \%$ & 0 & \\
\hline \multirow[t]{2}{*}{ Marital Status } & Married & 8 & $48.0 \%$ & 2 & $52.0 \%$ & 0 & 0.522 \\
\hline & Other & & $57.1 \%$ & & $42.9 \%$ & 4 & \\
\hline \multirow[t]{4}{*}{ Children } & 1 Child & & $75.0 \%$ & & $25.0 \%$ & & 0.436 \\
\hline & 2 Children & 1 & $52.5 \%$ & 9 & $47.5 \%$ & 0 & \\
\hline & 3 Children & 6 & $44.4 \%$ & 0 & $55.6 \%$ & 6 & \\
\hline & $>=4$ Children & 0 & $45.5 \%$ & 2 & $54.5 \%$ & 2 & \\
\hline \multirow[t]{2}{*}{ Family Income } & $<500$ Euro & 0 & $47.6 \%$ & 2 & $52.4 \%$ & 2 & 0.806 \\
\hline & $>500$ Euro & 6 & $50.0 \%$ & 6 & $50.0 \%$ & 2 & \\
\hline \multirow[t]{3}{*}{ Working } & Housewife & 8 & $45.9 \%$ & 3 & $54.1 \%$ & 1 & 0.759 \\
\hline & Retired & 1 & $52.5 \%$ & 9 & $47.5 \%$ & 0 & \\
\hline & Work & & $53.8 \%$ & & $46.2 \%$ & 3 & \\
\hline \multirow[t]{4}{*}{ Education } & Less than Primary & 0 & $42.3 \%$ & 1 & $57.7 \%$ & 1 & 0.140 \\
\hline & Primary & & $61.5 \%$ & & $38.5 \%$ & 3 & \\
\hline & Secondary & & $100.0 \%$ & & $0.0 \%$ & & \\
\hline & University & 4 & $53.8 \%$ & 2 & $46.2 \%$ & 6 & \\
\hline \multirow[t]{2}{*}{ Self reported Health } & Other & 3 & $42.3 \%$ & 5 & $57.7 \%$ & 8 & 0.032 \\
\hline & Good/Very Good & 3 & $63.9 \%$ & 3 & $36.1 \%$ & 6 & \\
\hline
\end{tabular}

[60] Hellenic Journal of Nursing Science 